\title{
Teaching sustainability, ethics and scientific writing: An integrated approach
}

Ola Leifler, Lars Lindblom, Mikael Svensson, Madelene Gramfält and Arne Jönsson

The self-archived postprint version of this journal article is available at Linköping University Institutional Repository (DiVA):

http://urn.kb.se/resolve?urn=urn:nbn:se:liu:diva-171518

N.B.: When citing this work, cite the original publication.

Leifler, O., Lindblom, L., Svensson, M., Gramfält, M., Jönsson, A., (2020), Teaching sustainability, ethics and scientific writing: An integrated approach, Proceedings of 2020 IEEE Frontiers in Education Conference (FIE). https://doi.org/10.1109/FIE44824.2020.9274220

Original publication available at:

https://doi.org/10.1109/FIE44824.2020.9274220

Copyright: IEEE

http://www.ieee.org/

(C)2020 IEEE. Personal use of this material is permitted. However, permission to reprint/republish this material for advertising or promotional purposes or for creating new collective works for resale or redistribution to servers or lists, or to reuse any copyrighted component of this work in other works must be obtained from the IEEE. 


\section{Teaching sustainability, ethics and scientific writing: An integrated approach}

\author{
$1^{\text {st }}$ Ola Leifler \\ Dept. of Computer and Information Science \\ Linköping University \\ Linköping, Sweden \\ ola.leifler@liu.se
}

\author{
$2^{\text {nd }}$ Lars Lindblom \\ Department of Culture and Society \\ Linköping University \\ Linköping, Sweden \\ lars.lindblom@liu.se
}

\author{
$3^{\text {rd }}$ Mikael Svensson \\ Dept. of Management and Engineering \\ Linköping University \\ Linköping, Sweden \\ mikael.svensson@liu.se
}

\author{
$4^{\text {th }}$ Madelene Gramfält \\ Department of Thematic Studies \\ Linköping University \\ Linköping, Sweden \\ madelene.gramfalt@liu.se
}

\author{
$5^{\text {th }}$ Arne Jönsson \\ Dept. of Computer and Information Science \\ Linköping University \\ Linköping, Sweden \\ arne.jonsson@liu.se
}

\begin{abstract}
This Innovative Practice Full Paper presents an approach to integrate three critical elements in Computer Science education.

The call to imbue computer science graduates with strategic skills needed to address our pressing global sustainability challenges is extremely important, and a great challenge to degree programmes in computer science and software engineering. Doing this successfully requires great care, and possibly several iterations across an entire curriculum. In this regard, learning for sustainability faces similar challenges as understanding scientific results and ethics. Improving skills in searching for, reading, and producing academic texts are often neglected, as are skills in understanding ethics; what norms and values that guide our choices of methods for solving problems. To handle the fact that these subjects (academic writing, ethics and sustainability) are treated separately, and thereby lowering student engagement with the topics, we have successfully integrated them into one coherent subject of Professionalism in Computer Science. By integrating the three subjects, we do three things: a) describe a multi-faceted but integrated engineering role; b) integrate the three aspects of the role we focus on in education and steer away from the view that these are add-ons; and c) increase the motivation of students to take on these aspects of the engineering role.

Our approach uses a flipped-classroom style with students playing educational games, participating in discussion seminars and conducting critical analyses of other students' choices in IT system design. Much emphasis is on the students academic writing abilities, including critical information search and a student peer-review procedure. Also, we do this using an integrated assessment format where teachers from different disciplinary backgrounds jointly assess material from students, which stimulates discussions among ourselves about what and how to assess, and provides a practical way to integrate assessments. We present results from attitude surveys, course evaluations and the contents of the students' analyses in their final essays. In conclusion, our approach demonstrates a clear shift in how students perceive sustainability, showing that it is possible to achieve changes in attitude towards the subjects as such and their importance for computer scientists.
\end{abstract}

Index Terms-Computer Science Education, Ethics, Scientific Writing, Sustainability, Flipped Classroom, Serious Games, Attitude Survey

\section{INTRODUCTION}

Facebook and Bitcoin are examples of successful software enterprises that have had outsized effects on the world. Through Facebook, we can connect to family and friends even if far apart. Bitcoin aspires to democratize currencies and redistribute the power over monetary systems. However, we are acutely aware of how these software systems and their business models have come to pose serious risks to society and become powerful, unaccountable entities. Facebook creates a giant echo-chamber for users by targeting them with userspecific news-like content that drive them to mistrust others who do not read what they do [12], and Bitcoin transactions are so computationally demanding that a single transaction costs the equivalent of a month's worth of electricity for an average US household [8]. Design decisions made by IT professionals, and business models designed around those designs, are at the heart of these issues. As IT systems become ever more powerful and pervasive in society, IT professionals must begin to assess potential long-term effects of their designs and assume responsibility for them.

Just as IT engineers are responsible for the design of Facebook content selection algorithms and the Bitcoin transaction verification mechanism, other professional groups are of course responsible for choices of business models around them. The competencies needed for IT professionals to contribute to a more sustainable world are not in principle different from the general competencies that have been identified as critical to contribute to societal change towards sustainability in general. Those competencies, described by both Wiek et al. [23] and UNESCO [21], include an ability to understand the principles for how complex systems, such as businesses, ecosystems or the climate system work and how they can change. They also include abilities to recognize, reason about systems of values and act according to your own, and to deal with conflicts between the values of different stakeholder. 
Crucially, they include affective competencies related to values and emotions, and competencies related to behaviours. That is, these competencies are not just about dry reasoning or analysis but engagement, commitment and behavioural change towards sustainability.

Integrating such topics in engineering in general or computer science programmes in particular has been slow. One reason might be that students form an identity around solving well-defined computer programming puzzles and become less and less interested in applying their skills on real-world problems during their degree programmes [16]. Even educators and Computer Science faculty express low levels of awareness and engagement [18], and are not working effectively to rethink curricula in light of the necessary societal changes. A different mindset may be needed by both students and teachers [13], one that includes recognition of the severity and relevance of global challenges for computer science professionals and researchers (for instance, as described in the Karlskrona Manifesto for Sustainability Design [3]). Our ambition, when given the task to design a course that would feature learning goals related to reading and writing scientific papers, ethics and sustainability, we opted to take a more holistic view than before on the integration of these issues, and present our approach in this paper.

Thus, we present our course Professionalism in Computer Science, its integrated approach and our experience from two years of giving the course, with 35 students each year. In Section II we discuss previous experiences from teaching ethics and academic writing and the obstacles we have encountered. In Section III we present the teaching methods that have been used in the course. The course design is presented in Section IV, and Section V presents results from the various evaluations that have been conducted. In Section VI we finally discuss our results and experiences from this integrated approach to teaching engineering students to be responsible software engineers and producers of science.

\section{EXPERIENCES OF INTEGRATING ETHICS, SUSTAINABILITY AND ACADEMIC WRITING}

Our integrated approach is partly motivated by our previous experience with integrating ethics and academic writing in a variety of engineering subjects, not only computer science.

\section{A. Integration of ethics in engineering/other subjects}

A common idea is that engineering is a very straightforward enterprise. The engineer uses his or her technological knowledge to solve the problems that he or she is asked to solve. This, however, is a much too simple characterisation [17]. Engineering is seldom about simple application, but about making choices, and sometimes these choices are difficult. Ethics is the scientific field that deals with analysing hard choices and providing suggestions about how conflicts between values or interests can be resolved. Indeed, there are interesting structural similarities between problem-solving in engineering and ethics [4]. In this way, ethical theory alongside with mathematics and the scientific method, provides useful tools for IT engineers. However, this case is often difficult to make in a convincing manner to students.

There are a least two reasons for this difficulty. On the side of ethics teachers, there can be a tendency to assume that students will find study of ethical theories either intrinsically rewarding or obviously relevant for their future profession. On the side of student, the idea of engineering as application makes education in ethics seem irrelevant. These two problems can be overcome if the teacher makes an effort to show how engineering and ethical theory are connected. Instead of starting by outlining, e.g., the intricacies of utilitarianism, one can start by showing that the practical problems in engineering may have to do with fundamental ethical concepts and trade-offs. One example of this could be how solutions to the problem of bias will have to combine sophisticated mathematics with an analysis of the value of fairness [1]. Other examples could be the issues we noted above regarding Bitcoin and Facebook. If this can be made clear to students, the need for training in ethics for future computer scientists is justified by the goal of one's future profession. This approach also has the advantage of showing the students the need for thinking about, at least to some extent, the intricacies of utilitarianism. The reason that this approach has a better chance of being a successful approach to teaching ethical theory to engineering students is that it makes use of their inherent motivation to become engineers. In this way, it can also overcome the idea of engineering as simple application of technical knowledge to well-defined problems.

\section{B. Integration of academic writing in engineering/other sub- jects}

It is generally agreed that academic writing is an essential part of any graduate program. However, there is less consensus on how academic writing should be incorporated in the curriculum. The approach of integrating the practice of writing with discipline specific courses is often referred to in terms of the concept of "Writing across the curriculum" (WAC), which has been widely adopted since the early 80s [14]. Still some diverging views exist on what pedagogical purpose academic writing should serve when included as part of a course or programme. Essentially the division can be described as the difference between "writing to learn" and "learning to write" [6]. In the former, writing becomes a method for introducing new knowledge by requiring the students to actively explain and describe concepts and relationships in the process of producing different types of texts. In the latter, the emphasis is on familiarising the students with the different types of writing that are central within a discipline, e.g the organisation and register of writing lab reports.

In practice, however, there is no inherent conflict between these two approaches, and ideally, the aims of both should be achieved as part of the academic writing training that students receive at graduate level. Unfortunately, the amount of resources that can be allocated to teaching and giving feedback on students' writing is often limited. There is therefore a tendency to emphasise the goals of "writing to learn" and 
assessing students writing primarily from the perspective of whether they have learnt and been able to apply the new concepts and ideas that have been introduced. Improving students' proficiency in writing is normally more resource intensive and require iterations of writing and teacher feedback. The need for resources is especially true, when the students are writing in a language that is not their native tongue. In addition, there is often less acceptance among students to take part in tasks of language proficiency training as this is either considered to be skills they already possess or skills that are outside of the main focus of their studies.

However, to design a course that effectively improves students' academic writing ability requires a recognition that methods of both "writing to learn" and "learning to write" must be included, and also that students are given writing tasks that they perceive as relevant within their field of study [19]. Even with these design goals in place, it is challenging to find a way to provide the students with sufficient amount of feedback that enables them to improve their writing. An approach that has been implemented with some success is the use of collaborative writing techniques, where students provide feedback to each other through peer reviewing [11], [22]. In addition to giving students more feedback on their writing by complementing teacher feedback with feedback from their peers, it has been reported that peer reviewing has increased the students' involvement and improved other skills such as critical thinking [15].

\section{LEARNING METHODS FOR ENGAGING STUDENTS IN ETHICS, SCIENTIFIC WRITING AND SUSTAINABILITY}

Learning to contribute to a sustainable development as an engineer means to understand norms and values that underlie the development of technical systems and how engineers are thus made to care primarily about short-term technical gains of technical development, to be able to analyse complex socio-technical systems in which engineers are key actors in mediating change, and to understand the scientific underpinnings of climate change that make calls for a rapid societal transformation imperative. Taken together, this means that understanding ethics, thinking in terms of systems and learning to process scientific knowledge in general and sustainabilityrelated papers in particular are key competencies to contribute to a sustainable development.

\section{A. Flipped classroom as an effective learning method and group discussions}

Obtaining knowledge has never been as easy, or as complicated, as today. The internet contributes with a wide range of, not only knowledge itself, but platforms where this knowledge can be gathered. One might be interested in a particular topic, and choose to watch a 3-minute tutorial on YouTube, listen to a podcast or search for rigorous open access research. The access to knowledge has moved from books, encyclopedias and single experts to a quick google search. This societal change of course affects the educational room. It is difficult to maintain traditional terms of teaching, where the teacher is seen as the knowledge authority. During the last years the field of education has tried to make use of the access to the multiplex resources outside the classroom. Today, flipping the classroom has become a way to move away from conventional teaching and instead integrating a raft of (digital) resources.

A flipped classroom means moving what is traditionally done in a classroom to be done at home, and what is traditionally called homework is moving into the classroom [20]. A flipped classroom means student-centred learning where the student is offered different tools to acquire knowledge on his or her terms, e.g., when, where and how much. The teacher, on the other hand, moves away from being only the provider of knowledge to a person who also can deepen the understanding, answer questions, inspire the students, and so on.

Pedagogical design is crucial when working with flipped classrooms, especially in an interdisciplinary course where students come from diverse educational and cultural backgrounds. One way to make use of this diversity is to gather the students around a given subject in constellations of group discussions. The discussions can be implemented in lectures as well as in seminars, and creates opportunities for the students to further deepen and contextualise their knowledge by listening to and discussing with students who have different points of view.

This multiplicity of views is very difficult (if not impossible) for a single, traditional knowledge-providing teacher to give the students, and therefor the use of different constellations of group discussions is crucial. To discuss a common subject in a group often results in enhancement of understanding of analysis, problematising, contextualising, implementation, etc. Students may find connections to their own experiences, or evoke questions which cannot be solved within the group. Also, perhaps especially in a diverse group of students, each participant is forced to motivate their statements, no matter if it is a personal opinion, experience or a scientific fact. The mix of students' backgrounds and their experiences do in many ways contribute to a sum bigger than its parts.

\section{B. Pedagogical games as a tool for learning about values and complex systems}

Active learning methods require student engagement in the classroom. To stimulate engagement, pedagogical games have been used successfully in training students' ability to understand values as well as complex system dynamics [7]. Pedagogical games come in several different flavors, such as role-playing games, digital games and board games. The field of serious games is now fairly well established and provides empirical evidence that games (especially immersive simulations) are effective in both promoting higher level skills as well as positive changes in attitudes and behaviours [5]. As a special type of serious games, board games offer the possibility to engage students in the classroom with welldefined formats of engagement and clear rules. In medical settings, they have been demonstrated to significantly improve students retention of knowledge and indirectly affect healthrelated behaviour as a result [10]. Although there may be even better ways to have students experience differences of 
values than playing board games (e.g. through interactions with people from different backgrounds who hold genuinely different opinions about values and goals, that students need to understand and handle), they offer classroom-based formats for learning that fit very well with existing systems of higher education. Together with a flipped-classroom-based approach, students get to prepare at home, come to classroom settings to practice, have fun and be challenged in a psychologically safe setting, and reflect on the outcome afterwards. Board games can serve to motivate students to participate, challenge them to do things like discuss and defend opinions that are not their own in a safe manner, and provide them with tangible experiences that they are able to reflect on and learn from. In our course, we make use of all these affordances of the two board games Dilemma and Fish Banks.

\section{Integrating systems thinking and values thinking in assess- ing the effects of IT systems}

After students have conducted classroom activities that trigger reflections on values and behaviours, they need to become aware of how these experiences are applicable in their own domain of expertise. Software engineers are not always used to consider long-term effects of systems that they build and may need help to build awareness of issues that span multiple domains over longer periods of time. One way to build awareness is through the requirements elicitation process [2]. During that process, it can be effective to have someone ask specific, critical questions about potential effects that an IT systems design can have on users, the community, economical systems, ecosystems or the technical system itself over time [9]. The key to successfully raising awareness of potential long-term issues, according the 2019 study by Duboc et al. [9] is to have external reviewers, preferably with an expertise in the particular issues being discussed, ask critical questions about system design. Duboc et al. introduce a structured framework for raising awareness of potential sustainability issues in software design, called the Sustainability Awareness Framework, or SusAF. In our course, we had our students use SusAF to ask critical questions to a group of students in a parallel entrepreneurship course, who were designing IT systems that they wished to develop business models for. SusAF requires students to ask specific questions about potential long-term effects that could either be derived directly from the specifications of the system (such as making $\mathrm{CO} 2$ footprint a visible property of products available in a procurement system), or from indirect, enabling or inhibiting effects (such as enabling users to make purchasing choices based on information on carbon impact), or from having a whole company or community use a system (such as reducing the climate impact of purchases). After asking such questions, the interviewers and interviewees had to create diagrams with chains of potential effects, analyzing whether negative ones could be mitigated or positive ones be realized. This analysis became the basis for our students' final assignment.

\section{Course Design}

The course is designed with the aim to prepare computer science students for academic studies at an advanced level and prepare them for the responsibilities they will have to assume in the future. That is, the course is designed to provide essential tools for the transition from passive consumers of science and technical know-how to active and conscious participants in shaping the future. A basic ambition is to give the students a broader perspective on society and the role of Computer Science in society. Of special importance is the responsibilities and possibilities of computing professionals to not only produce useful software but also to reflect on ethical responsibility and software developers role for a sustainable society. The course is mandatory for first years students in the Masters's program in Computer Science.

\section{A. Goals and course format}

Three subjects are integrated in our course design, with individual learning goals for each subject:

Academic writing including the writing process, principles for review of written reports, and constructive criticism. The aim is also that the students know about the use of library resources, the meaning of the academic approach, and similar issues on the conditions for science. Ethics includes to account for common ethical theories, principles and concepts as well as to apply them to specific cases and situations. The aim is also for students to be able to present and discuss ethical challenges related to computer technology development and use, to demonstrate insight into the role of knowledge in society and on people's responsibility for how it is used, and to demonstrate the ability to make judgements in computer science with regard to relevant ethical aspects. Sustainable development includes the ability to identify and describe examples of sustainability aspects related to the field of computer science, explain and discuss the relevance of computer technology for sustainable development, compare and evaluate computer science's possibilities and constraints in society as well as peoples' responsibility for how they are used in a sustainability perspective. The students also need to reflect on and critically review sustainability and sustainable methods in computer science, analyze the consequences of computer technology applications on sustainable development and suggest system designs that take these consequences into account.

The course consists of interactive lectures and seminars where students need to be prepared, and participate in discussions on themes concerning ethical issues, societal challenges and the role of computer science.

The seminars are all flipped classroom and require preparations that has to be handed in before the seminar. During the seminars the students scrutinise the material in smaller groups, 6-8 students, that are formed initially in the course and then maintained throughout the whole course.

The subjects are further integrated as the lectures, and especially the seminars, comprise elements of each subject. For instance, two seminars are devoted to playing board 
games, namely Dilemma (played twice) and Fish Banks. Dilemma introduces students to both subject-matter knowledge about the state of the world and to our global challenges, as well as dilemmas inherent in dealing with them. Fish Banks introduces the tragedy of the commons inherent in fishing, forestry or climate change. The societal dilemmas that these games raise comprise a number of ethical issues as well as how different dimensions of sustainability are interrelated and how IT systems have effects on individuals, organisations and societies. These issues are then discussed in ensuing seminars. The written preparations are not only assessed from a content perspective but also from the perspective of information search, constructive criticism, and academic writing.

The course is assessed through a series of related writing assignments. Some of these writing assignments involves answering specific content questions, reading scientific papers or conducting other tasks. The students also write a longer essay throughout the course, which is the basis for assessing abilities related to all three themes. The essay is submitted at three times with different themes. The first two themes concern basic tenets of sustainability and IT in society. The second two themes concern responsibilities of IT professionals and systems thinking. The final theme concerns the effects a particular IT system has from a systems perspective, as well as related to the responsibilities of IT professionals. The latter is based on interviews with, for instance, software entrepreneurship students.

The different parts of the essay are refined iteratively by the students in the groups that also met during the seminars. Before each such seminar the students read, and constructively comment, in writing, on two other students essays. At the seminar the teacher and the students, in groups, discuss each students essay from all aspects, i.e. academic writing, ethics and sustainability. Thus, all perspectives are integrated and discussed during the seminars and, as the students peer-review their essays, the discussions can be much more focused. To further guide the students there are detailed grading criteria for each subject on the course' web pages. This helps the students focus and ensures that all important aspects are covered in the essay.

\section{B. Five types of integration}

As seen above, one way of achieving engagement in ethics education for engineers is to show how ethical theory and engineering practice can connect. We have also seen how professional writing can be taught in a fruitful way if combined with more standard topics in engineering. Moreover, sustainability raises a multitude of issues are intimately connected to engineering practice. Such ideas of integration form the backbone of our approach. This section illustrates how the course is designed to achieve integration on five levels.

The first of these levels has to do with engineering itself. The course assumes that an engineer needs to be in possession of technical knowledge and an understanding of science. However, it does not stop there. To be an engineer in a full sense, one needs to have knowledge of important issues regarding the world in which one works. Few issues are of higher importance at present than the threat of global warming, and the course takes sustainability as a topics. There is more to engineering than the solving of problems, one must also be able to communicate one's solutions, which is why our approach includes professional writing. Moreover, engineering is a profession of trade offs and to prepare the students for this, the course includes ethics as a topic. A first level of integration is, then, to integrate standard topics in engineering with ethics, professional writing and sustainability to provide a full account of a professional role as computer engineer.

However, the fact that a collection of topics is taught in a course does not necessarily mean that they give the student the impression of being an integrated whole. Subjects like ethics, professional writing and sustainability can sometimes seem like unnecessary add-ons. To avoid this mistaken impression, the way teachers work is also integrated. This means that workshops that focus on sustainability are followed by seminars on ethics, with the ethics teacher present during the workshop as well as the seminar. This takes some planning, so that different topics and forms of teaching follow each other in the appropriate way and that teachers can take part in different parts of the course, outside their own topics, in a useful way. Grading is also integrated, with different teachers taking on different aspects of the papers. These forms of integration improve teaching and illustrate for the students that the approach to engineering presented during the course is an integrated whole.

A third level of integration takes place outside of the classroom. We let the students use what they have learned during the course in interactions with organisations, or other students, outside of class. The students conduct interviews regarding projects that are relevant to the future profession and are asked to analyse them using the tools provided by the course. This shows the students the usefulness of the tools as well as how they are integrated aspects of engineering, and should improve motivation to learn them. Cooperation with the outside world is, then, another level of integration.

A further level of integration has to do with the composition of the student group. The course participants come from all parts of the world. This has turned out to be a further advantage of the course design, since it has allowed us to integrate intercultural perspectives on engineering, ethics and sustainability and enrich class discussions. It has also helped illustrate that there are many different approaches one can take to normative issues and showed the need for systematic reasoning about such topics.

A fifth level of integration can be found in the assignments that students write during the course. This has both a temporal and a substantive aspect. The final essay is written during the entirety of the course with several submissions and designed to be redeveloped and enlarged when new knowledge is acquired. This temporal aspect of integration also allows for a substantive integration of the topics of sustainability and societal problems and IT in society, responsibility and systems thinking, and finally the effects of IT systems analysed in terms 
of the prior parts of the essay. This illustrates the multifaceted characteristics of a professional approach to engineering, as well as the integrated nature of the materials presented during our course. The point of integrating these five levels is to illustrate that issues of sustainability, professional writing and ethics are indispensable to the professional conduct of computer engineers and thereby to motivate students to take these topics seriously.

\section{Student peer review, implementation and experiences}

From the perspective of academic writing, the design of the course provides many opportunities for the students to write, which is essential for improving their proficiency, and although some of the student are less familiar with the essay format and argumentative writing, the writing assignments generally work well both as a way for the students to consolidate and develop their knowledge of the subject matter, and as a way to introduce them to different aspects of academic writing.

However, the use of collaborative writing and the emphasis of peer reviewing as a way for the students to receive feedback on their writing at different stages of the text production require that students enter the course with a fairly good level of general language proficiency, and that they already from the start of the course are able to both produce and receive productive feedback. When these conditions are met, the design of the course works well, and allows the students to improve both in terms of the content and their writing skills. On the other hand, when the students language skills are less developed, or when they are unfamiliar with the method of peer reviewing, the feedback they give and their ability to make use of the feedback they receive become less effective. To handle these obstacles and improve the outcome of the academic writing element of the course more of the teaching resources related to writing need to be placed early on in the course, with more effort on teaching the students to both give and receive productive feedback.

\section{Evaluation}

The course has been assessed from a number of perspectives including attitude surveys, teacher experiences and the quality of the students' essays. The goal has been to combine several sources and methods of evaluation to achieve a multidimensional picture of the outcomes of the course, including changes in attitudes, competencies and the grasp of factual information. Unfortunately the anonymous course evaluations had low response rates. The overall course ratings were both years above mean ( 3 on a 5 grade scale), but we feel unable to draw conclusions from only those. The course evaluations are handled by the central student administration but we will further encourage the students to fill them in. However, due to the multidimensional approach to evaluation that we have taken during this course, we believe that clear positive effects of our course design can be identified.

\section{A. Attitude survey design}

An important motivation for us in integrating subjects, students and teachers in the course was to stimulate changes in students' attitudes. As a simple assessment of how students attitudes towards science in general, ethics and sustainability were affected (if at all), we asked questions regarding what they believed best described each, and how they reasoned about their respective importance. We presented them with questions that were intended to capture the degree to which they viewed science, ethics and sustainability as directly related to their own identity as future software professionals. To achieve this, we formulated response options that represented the attitude that science or ethics is mostly concerned with academia or that they are frames for thought available for anyone. Also, we included response options intended to capture naive conceptions of science and ethics that we believed our students might hold if they had not considered science or ethics important tools for their future careers. In the same way, we wished to capture if the students understood the concept of sustainable development as primarily concerning technological improvements of current socio-technical systems, or if they were able to recognize other potential perspectives on, or definitions of, a sustainable development. Also, we wished to know if their perception of sustainability was related to different decision-making situations. For instance, was their attitude concerning the relationship between sustainability and technical development related to their perceptions of when sustainability concerns would matter to them (professionally or personally). Our motivation here was to see if students attitudes towards sustainability (i.e., based on techno-centric, anthropocentric or ecocentric views of sustainability) had any effects on their assessment of how important it would be for them to make decisions in different situations based on concerns for a sustainable future.

First, we asked before the course whether they took our course as their first ever in scientific writing, ethics or sustainability (at university level). Second, we asked what they believed best described science: a set of facts about the world, an approach to thinking about the world, an activity carried our in academia, or an activity carried out by professional researchers. They could select more than one option (even though we wished for them to select the one they believed best described science). We also asked how important they thought science would be for them in their personal life, studies and future careers. Third, we asked how they thought ethics is best described: as a set of ideals to act according to, a framework for reasoning about values, or an academic discipline for studying ethical behaviour. Again, they could select multiple options. The options reflected the options related to science as we wished to see if students saw ethics and science as something concerning others (professional researchers) or themselves, and whether they mainly recognised fixed knowledge or disciplines of inquiry. We also asked the same question regarding importance in their own lives. Fourth, we asked if they believe sustainability would be best described as (a) developing technology for a better world, (b) developing technology with less resources consumption, (c) ensuring that our current society can be sustained, (d) ensuring that all forms of life as we know them can be sustained over the long term, or 
(e) ensuring lasting prosperity for all people on Earth. Finally, we asked if they believed that the concept of sustainability would be important to them in deciding jobs to take or projects to work on, making decisions when designing IT systems, or making decisions as a customer.

All questions except the first were asked both before and after the course for two editions of the course and almost all participants responded each time as we devoted 10 minutes in class to collectively answer these brief surveys.

\section{B. Attitude survey results}

For most of the students in the course, this was their first course at university level in both scientific writing, ethics and sustainability (see Table I). The fewest (9 of 37) had taken a course with some aspects of sustainability before. It was somewhat surprising that less than half of the students had taken courses in either scientific writing or ethics, as both subjects tend to be seen as core aspects of higher education bachelor's degree programmes in general.

Our conceptual questions regarding how students characterised science (see Table II) revealed that after the course, they were slightly more inclined to associate science in general with being an academic endeavour, but overwhelmingly, they considered science as an approach to thinking about the world. Their descriptions of ethics (see Table III) shifted as well, so that after the course they were more inclined to frame ethics as an academic discipline but also less of a fixed set of ideals and more a framework for reasoning about values.

Their view of sustainability shifted too, but in a different way (see Table IV). Here, the strongest trend was that they saw sustainability as a wider term than associated with technology. Most chose to even adopt the widest ecocentric view, that all forms of life should be sustained over the long term.

The final part of the survey which concerned their expected future involvement with the themes of the course showed that for science and ethics (Table V), students only reported increases after the course in the appreciated importance in their personal life, studies or future professions. For sustainability, they moved slightly away from the notion that sustainability is of concern mostly as consumers and not so much as designers of IT systems (Table VI), and towards an appreciation of sustainability as important in their future careers as well.

\section{Teacher experiences and challenges}

The course is taught by teachers from five different disciplines: computer science, ethics, linguistics, library science and sustainability science. During the course we all gained a deeper understanding of the respective subjects and how we,

Table I

RATE OF RESPONDENTS HAVING OUR COURSE AS THEIR FIRST IN EACH SUBJECT $(\mathrm{N}=37)$

\begin{tabular}{l|l} 
First course in scientific writing? & $56,8 \%$ \\
First course in ethics? & $59,5 \%$ \\
First course in sustainability? & $75,7 \%$
\end{tabular}

Table II

DEFINITIONS OF SCIENCE BEFORE THE COURSE AND AFTER

\begin{tabular}{l|c|c} 
"What would you say best describes science?" & Before & After \\
\hline \hline A set of facts and knowns about the world & $59,5 \%$ & $52,3 \%$ \\
An approach to thinking about the world & $62,2 \%$ & $63,6 \%$ \\
An activity carried out in academia & $5,4 \%$ & $9,1 \%$ \\
An activity carried out by processional researchers & $10,8 \%$ & $15,9 \%$
\end{tabular}

Table III

DEFINITION OF ETHICS BEFORE THE COURSE AND AFTER.

\begin{tabular}{l|c|c} 
"What would you say best describes ethics?" & Before & After \\
\hline \hline A set of ideals to act according to & $59,5 \%$ & $47,6 \%$ \\
A framework for reasoning about values & $45,9 \%$ & $50 \%$ \\
An academic discipline studying ethical behaviour & $18,9 \%$ & $21,4 \%$
\end{tabular}

as teachers, can integrate this to make our own subject more interesting; not only in this course.

The integrated approach has clearly facilitated the students' understanding of their role as responsible professional computer science engineers. In the classroom, during the discussion seminars, when playing the various games and in the lectures, our experience, as teachers, is that the students are very active. In case some students failed to make the required preparations, they noted in the game sessions that they failed to provide answers to questions or defend positions in debates. During the debriefing sessions after our game seminars, we let the different groups bring up what they learned and the students could then articulate themselves whether they and their group members were well prepared. We also noticed that the students saw the three subjects as integrated, as they made use of the different subjects during the final seminars of the course. The writing, and marking, of the essay has been another interesting challenge. For many of the students this is the first time they are to present their own, educated, viewpoint; a viewpoint that often includes a certain amount of fuzziness that can, and shall, be debated. Such is not present in their normal computer science courses. For us as teachers, with our different backgrounds, it has been an interesting journey to follow, and learn from, other subjects. To facilitate this we developed very detailed assessment criteria for the final integrated essay, grading criteria that, for each subject, presented the learning outcomes and how that was assessed. These were also used by the students when they peer-reviewed the other students essays.

Being teachers from different disciplines, we have had to synchronise information about the course format and assessments. In this work, we have experienced challenges in making sure that all information towards students is consistent and complete, and that our own ideas about learning goals and formats have been challenged. Getting this right has not been straightforward, but very fruitful for furthering our own understanding of what we wish to achieve in the course. As we have had our regular meetings, during which we have worked to integrate our different disciplines, we have forced ourselves to understand and synchronise each others' learning activities and assessment criteria. 
Table IV

DEFINITION OF SUSTAINABILITY BEFORE THE COURSE AND AFTER.

\begin{tabular}{l|c|c} 
"What would you say best describes sustainability?" & Before & After \\
\hline \hline Developing technology for a better world & $43,2 \%$ & $36,4 \%$ \\
Developing technology with less resources consump- & $40,5 \%$ & $31,8 \%$ \\
tion & & \\
Ensuring that our current society can be sustained & $18,9 \%$ & $36,4 \%$ \\
Ensuring that all forms of life as we know them can & $51,4 \%$ & $72,7 \%$ \\
be sustained over the long term & & \\
Ensuring lasting prosperity for all people on Earth & $18,9 \%$ & $27,3 \%$
\end{tabular}

Table V

RESPONSES TO THE QUESTIONS ON THE IMPORTANCE OF SCIENCE AND ETHICS, AVERAGES ON A SCALE FROM 0-3 BEFORE THE COURSE AND AFTER.

\begin{tabular}{l|c|c|c|c} 
How important do you think A & \multicolumn{2}{|c|}{$\begin{array}{c}\text { A=Science } \\
\text { will be in B? }\end{array}$} & \multicolumn{2}{c}{ A=Ethics } \\
wefore & After & Before & After \\
\hline \hline B="In personal life" & 2,30 & 2,39 & 2,43 & 2,70 \\
B="'In studies" & 2,70 & 2,70 & 2,24 & 2,30 \\
B="Future profession" & 2,43 & 2,70 & 2,38 & 2,57
\end{tabular}

\section{Student essays}

A core instrument for tracking the development of the students during the course is the final paper. It is written and refined during the entirety of the course, and should show increasing levels of competence with regards to professional writing, sustainability and ethics from first draft to the conclusion of the final version. In this way, we have included a qualitative method of evaluation in the course design, which also has the pedagogical advantage of making room for prodding development in student achievements by feedback from both the teachers and other students. Up until now this form of evaluation has been carried out in an informal manner, but what we see in the final papers is the kind of development we have planned for, with some rather sophisticated probing of complicated issues. As an example, one student indicated that he had learned about the difficulties of getting to an agreement about disputed issues like sustainability: "During my time as a student in computer science, I discovered that it is way easier to discover other people's flaws than my own". In other papers, difficult and unusual trade-offs were identified: "It could raise the question on whether the mental health or the environment should be prioritised." A recurring pattern was that students were thinking about their role as future professionals: "as a professional software engineer, I would prefer designing and working on products that have a stronger impact and make the world a better place." This, to us, indicates that the students have internalised the lessons of the course.

\section{DISCUSSION AND CONCLUSIONS}

We have presented an approach to teach masters' students in computer engineering to become professional, in the sense of being responsible software developers that reflect on ethical responsibility, understanding the importance of sustainability, and being able to understand scientific studies and correctly present their own work. Such issues are not systematically covered in any other course, but are mandatory for Master's
Table VI

RESPONSES TO THE QUESTIONS ON THE IMPORTANCE OF SUSTAINABILITY, AVERAGES ON A SCALE FROM 0-3 BEFORE THE COURSE AND AFTER.

\begin{tabular}{l|c|c} 
How important do you think sustainability will be in ... & Before & After \\
\hline \hline decisions on jobs to take or projects to work on & 2,11 & 2,35 \\
decisions when designing IT systems & 2,22 & 2,32 \\
decisions as a consumer & 2,41 & 2,33
\end{tabular}

in Computer Science and must, for instance, be address in the final thesis.

The approach, which is implemented in the course Professionalism in Computer Science, is based on integration in various ways: three different subjects are integrated, teachers from different disciplines are integrated through a variety of learning methods, the students are integrated in project work outside the classroom, heterogeneous student groups are integrated, and student assessment is based on an integrated essay including aspects from all subjects. The integration on multiple levels is challenging, especially information to the students on the purpose of seminars, hand-in exercises, the integrated essay and peer-reviewing. We are also using two web sites, one public, primarily for information, and another for submissions, feedback, and assessments. The information management is something that can be improved in future work on the course. As one difficulty for feedback on the course is to achieve a high enough response rate in course evaluations, we have collected additional sources of information about the outcome of the course, such as the attitude surveys, teachers experiences and essay contents. Together, they provide support for our integrated design. The most important result, we would say, is that the students were highly motivated during the course and did not consider the three subjects as uninteresting or irrelevant for them in their future roles as software engineers. On the contrary, the discussions during the seminars and the discussions we had with the students showed that most were well prepared and could argue, and act, professionally.

Also, as teachers from different backgrounds, we have found this to be one of the more stimulating experiences in helping students with our respective subjects in a more engaging and integrated manner. Ultimately, we hope to inspire more teachers to use games, cross-group course designs and tight integration across teachers and disciplines. It may be frustrating, challenging but, with an open mindset, a highly rewarding way to teach.

\section{REFERENCES}

[1] Solon Barocas, Moritz Hardt, and Arvind Narayanan. Fairness and Machine Learning. fairmlbook.org, 2019. http: / /www.fairmlbook.org.

[2] Christoph Becker, Betz, Stefanie Chitchyan, Ruzanna, Leticia Duboc, Steve M. Easterbrook, Birgit Penzenstadler, Norbert Seyff, and Colin C Venters. Requirements: The key to sustainability. IEEE Software, 33(1):56-65, January-February 2016.

[3] Christoph Becker, Ruzanna Chitchyan, Leticia Duboc, Steve Easterbrook, Birgit Penzenstadler, Norbert Seyff, and Colin C Venters. Sustainability design and software: the Karlskrona manifesto. In IEEE International Conference on Software Engineering (ICSE), volume 2, pages 467-476. IEEE, 2015. 
[4] Bridget Bero and Alana Kuhlman. Teaching ethics to engineers: Ethical decision making parallels the engineering design process. Mediterranean Journal of Mathematics, 17(3):597-605, September 2011.

[5] Elizabeth A Boyle, Thomas Hainey, Thomas M Connolly, Grant Gray, Jeffrey Earp, Michela Ott, Theodore Lim, Manuel Ninaus, Claudia Ribeiro, and João Pereira. An update to the systematic literature review of empirical evidence of the impacts and outcomes of computer games and serious games. Computers \& Education, 94:178-192, 2016.

[6] Glenn J. Broadhead. Addressing multiple goals for engineering writing: The role of course-specific websites. Language and Learning Across the Disciplines, 3(2):19-43, 1999.

[7] Jon-Erik Dahlin. The merit of educational games in sustainability education. In Proceedings of the 8th Conference on Engineering Education for Sustainable Development (EESD), Bruges, Belgium, 2016.

[8] Alex De Vries. Bitcoin's growing energy problem. Joule, 2(5):801-805, 2018.

[9] L. Duboc, S. Betz, B. Penzenstadler, S. Akinli Kocak, R. Chitchyan, O. Leifler, J. Porras, N. Seyff, and C. C. Venters. Do we really know what we are building? raising awareness of potential sustainability effects of software systems in requirements engineering. In 2019 IEEE 27th International Requirements Engineering Conference (RE), pages 6-16, Sep. 2019.

[10] Andrea Gauthier, Pamela M Kato, Kim CM Bul, Ian Dunwell, Aimee Walker-Clarke, and Petros Lameras. Board games for health: A systematic literature review and meta-analysis. Games for health journal, 8(2):85-100, 2019.

[11] Vinícius Medina Kern, Luciana Martins Saraiva, and Robert Carlos Dos Santos Pacheco. Peer review in education:promoting collaboration, written expression, critical thinking, and professional responsibility. Education and Information Technologies, 8(1):37-46, 2003.

[12] Megan Knight. Explainer: how facebook has become the world's largest echo chamber. The Conversation, February 2018.

[13] Samuel Mann. A transformation mindset for computing education for sustainability. International Journal on Computer Science and Information Systems, 12(2):115-132, 2017.

[14] Susan McLeod. Defining writing across the curriculum. WPA: Writing Program Administration, 11(1-2):19-24, 1987.

[15] Vicente Matellán-Olivera Miguel Á. Conde, Lidia Sánchez-González and Francisco J. Rodríguez-Lera. Application of peer review techniques in engineering education. International Journal of Engineering Education, 33(2):918-926, 2017.

[16] Anne-Kathrine Peters. Students' experience of participation in a discipline - a longitudinal study of computer science and it engineering students. ACM Transactions on Computing Education, 19(1), 2018.

[17] Ibo van der Poel. Ethics, Technology and Engineering: An Introduction. Wiley and Sons, 2011.

[18] Ian Pollock, Bedour Alshaigy, Andrew Bradley, Birgit R. Krogstie, Viraj Kumar, Linda Ott, Anne-Kathrin Peters, Charles Riedesel, and Charles Wallace. 1.5 degrees of separation: Computer science education in the age of the anthropocene. In Proceedings of the Working Group Reports on Innovation and Technology in Computer Science Education, ITiCSEWGR '19, pages 1-25, New York, NY, USA, 2019. Association for Computing Machinery.

[19] Bruce Saulnier. The application of writing across the curriculum (wac) techniques in a systems analysis \& design flipped classroom. Information Systems Education Journal, 14(4):13-19, 2016.

[20] Bill Tucker. The flipped classroom. Education next, 12(1):82-83, 2012.

[21] United Nations Educational, Scientific, and Cultural Organization. Education for sustainable development goals - learning objectives, 2017.

[22] Anne Venables and Raymond Summit. Enhancing scientific essay writing using peer assessment. Innovations in Education and Teaching International, 40(3):281-290, 2003.

[23] Arnim Wiek, Lauren Withycombe, and CharlesL. Redman. Key competencies in sustainability: a reference framework for academic program development. Sustainability Science, 6(2):203-218, 2011. 